SPINE An International Journal for the study of the spine Publish Ahead of Print

DOI: $10.1097 / B R S .0000000000001887$

\title{
Braces for idiopathic scoliosis in adolescents
}

Stefano Negrini ${ }^{1}$, M.D., Silvia Minozzi ${ }^{2}$, M.D., Josette Bettany-Saltikov, PhD, $\mathrm{PT}^{3}$, Nachiappan Chockalingam ${ }^{4}$, $\mathrm{PhD}$, Theodoros B. Grivas ${ }^{5}$, M.D., Tomasz Kotwicki ${ }^{6}$, M.D., Toru Maruyama ${ }^{7}$ M.D., Michele Romano $^{8}$,PT, Fabio Zaina ${ }^{8}$, M.D.

${ }^{1}$ Physical and Rehabilitation Medicine, University of Brescia - IRCCS Fondazione Don Gnocchi Milan, Brescia, Italy

${ }^{2}$ Department of Epidemiology, Lazio Regional Health Service, Rome, Italy

${ }^{3}$ School of Health and Social Care, University of Teesside, Middlesbrough, UK

${ }^{4}$ Faculty of Health, Staffordshire University, Stoke-on-Trent, UK

${ }^{5}$ Department of Trauma and Orthopaedics, "Tzanio" General Hospital of Piraeus, Piraeus, Greece

${ }^{6}$ Department of Pediatric Orthopedics and Traumatology, University of Medical Sciences, Poznan, Poland

${ }^{7}$ Department of Orthopaedic Surgery, Saitama Medical University, Kawagoe, Japan

${ }^{8}$ ISICO (Italian Scientific Spine Institute), Milan, Italy

\section{Contact person}

\section{Stefano Negrini}

Physical and Rehabilitation Medicine

University of Brescia - IRCCS Fondazione Don Gnocchi Milan

Viale Europa

25121 Brescia

Italy

E-mail: stefano.negrini@isico.it

Acknowledgement: June 30, 2016

Accept: June 30, 2016

The manuscript submitted does not contain information about medical device(s)/drug(s).

No funds were received in support of this work.

Relevant financial activities outside the submitted work: grants, stocks. 


\section{Study Design}

A Cochrane Systematic Review

\section{Objective}

To evaluate the efficacy of bracing for adolescents with AIS versus no treatment or other treatments, on quality of life, disability, pulmonary disorders, progression of the curve, psychological and cosmetic issues.

\section{Summary of Background Data}

Idiopathic scoliosis is a three-dimensional deformity of the spine. The most common form is diagnosed in adolescence. While adolescent idiopathic scoliosis (AIS) can progress during growth and cause a surface deformity, it is usually not symptomatic.

\section{Methods}

Search methods

We searched CENTRAL, MEDLINE, EMBASE, five other databases, and two trials registers up to February 2015. We also checked reference lists and hand searched grey literature.

Selection criteria

RCTs and prospective controlled cohort studies comparing braces with no treatment, other treatment, surgery, and different types of braces for adolescent with AIS.

Data collection and analysis

We used standard methodological procedures expected by The Cochrane Collaboration.

\section{Results}

We included seven studies. Five were planned as RCTs, two as prospective CCT`s. One RCT failed completely, another was continued as an observational study. There was very low quality evidence from one small RCT that quality of life (QoL) during treatment did not differ significantly between rigid bracing and observation.

\section{Conclusions}

Two studies showed that bracing did not change QoL during treatment, and QoL, back pain psychological and cosmetic issues in the long term (16 years.) All papers showed that bracing prevented curve progression. The high rate of failure of RCTs demonstrates the huge difficulties in performing RCTs in a field where parents reject randomization of their children.

Key Words: Braces, adolescents, idiopathic, scoliosis, systematic review, observation, physical therapy

\section{Level of Evidence: 1}




\section{Background \\ Description of the condition}

Scoliosis is a three-dimensional deformity of the spine and the trunk [1]. The most common form is idiopathic scoliosis (70\% to $80 \%$ of cases) [1,2]. Adolescent idiopathic scoliosis (AIS) is discovered at 10 years of age or older [2], and is defined as a curve of at least $10^{\circ}$, measured on a standing radiograph using the Cobb technique [1]. While the prevalence of AIS is $0.9 \%$ to $12 \%$ in the general population [3], almost $10 \%$ of people diagnosed with AIS will require some form of treatment. Furthermore, up to $0.1 \%$ of the population is at risk of surgery [4,5]. A severe form of AIS is more commonly found in females (80\% to $90 \%$ ). Typically, AIS does not cause any health problems during growth (except for extreme cases). However, the resulting surface deformity frequently has a negative impact on adolescents that can give rise to quality of life (QoL) issues and in the most severe cases, psychological disturbances [6,7]. Adolescents are generally treated in an attempt to halt the progressive nature of the deformity. No treatments succeed in full correction to a normal spine, and even reduction of the deformity is difficult $[4,8]$. If scoliosis surpasses a critical threshold, usually considered to be $30^{\circ} \mathrm{Cobb}$, at the end of growth, the risk of health problems in adulthood increases significantly $[4,9,10]$. Problems include reduced QoL, disability, pain, increased cosmetic deformity, functional limitations, pulmonary problems, and possible progression during adulthood [8-17]. Because of this, management of scoliosis also includes the prevention of secondary problems associated with the deformity [18].

\section{Description of the intervention}

Treatment options for the prevention of AIS progression include exercises, bracing, and surgery [1,19-29]. Bracing can be defined as the application of external corrective forces to the trunk. This is usually achieved through rigid supports, but elastic bands are also used [30]. Treatment commences when the curve is diagnosed as progressive or exceeds a threshold, which is considered to be above $20^{\circ} \mathrm{Cobb}$, usually between $25^{\circ}$ and $30^{\circ}$ $[4,22,31]$. Braces should generally be worn full-time (at least 20 hours per day) with treatment usually lasting from a minimum of two to four or five years, until the end of bone growth [32-35]. All this causes a significant impact on the lives of children and adolescents [36-40].

\section{How the intervention might work}

The mechanical forces and the external and proprioceptive inputs of bracing can reduce unnatural loading and asymmetrical movements and improve neuromuscular control. This facilitates proper spinal growth, neuromotor re-organization, and change of motor behaviours [13,38,41-46].

\section{Why it is important to do this review}

Currently, the bracing of adolescents with AIS is controversial. It is considered standard treatment in continental Europe, but not in many centres of the UK, US, and elsewhere [2,47]. Bracing has been widely criticized because there is a paucity of evidence regarding its benefits [48-52]. Moreover, bracing has been linked to reduced QoL and increased psychological issues [36,37,39,40]. To date, reviews on braces have been mainly narrative, have not considered the key issue of evaluating the methodological quality of the studies in the review, and have not included all existing studies [20,29,51]. Our previous Cochrane review was based on only two studies and found inconclusive evidence [53]. An update of this review will help clinicians to decide whether the sacrifices required by children to wear braces are indeed worthwhile.

\section{Objectives}

To evaluate the efficacy of bracing for adolescents with AIS versus no treatment or other treatments, on quality of life, disability, pulmonary disorders, progression of the curve, and psychological and cosmetic issues.

\section{Methods}

\section{Criteria for considering studies for this review}

\section{Types of studies}

All randomized controlled trials (RCTs) and prospective controlled cohort studies.

\section{Types of participants}


We included all participants who were 10 years of age or older (until the end of bone growth) when diagnosed as having AIS. We included only studies in which bone maturity was evaluated by the Risser sign, wrist radiographs, or both. We excluded studies in which participants presented with any type of secondary scoliosis (congenital, neurological, metabolic, post-traumatic, etc.) diagnosed according to the Scoliosis Research Society (SRS) [35], and the international Society on Scoliosis Orthopedic and Rehabilitation Treatment (SOSORT) [1], criteria.

\section{Types of interventions}

We included all types of rigid, semi-rigid, and elastic braces (defined as devices to apply external corrective forces to the spine and trunk), worn for a specific number of hours per day for a specific number of years. We considered all possible control interventions and comparisons.

\section{Types of outcome measures}

Primary outcomes

Pulmonary disorders, disability, back pain, QoL, and psychological and cosmetic issues. We included only validated measures of study outcomes, and we assessed minimal clinically important differences on a case-bycase basis.

Secondary outcomes

Clinical and radiographic parameters [1,9]. Very short (any result before the end of bone growth), intermediate (results at the end of bone growth), and long-term (results in adulthood) outcomes. Progression of scoliosis was measured by:

- $\quad$ Cobb angle in degrees (absolute values);

- $\quad$ number of participants who had progressed by more than $5^{\circ}$ Cobb (radiographic measurement error, considered as the minimal clinically important difference) [1];

- $\quad$ risk of success, defined in terms of participants that at the end of treatment were neither treated surgically (fused) nor surpassing specific thresholds considered clinically meaningful ( $45^{\circ}$ or $50^{\circ}$, or both) $[1,31]$;

- $\quad$ Adverse effects, as outlined in identified trials.

\section{Search methods for identification of studies}

\section{Electronic searches}

For this update, we searched the following electronic databases to 17 and 18 February 2015 to identify relevant studies:

- $\quad$ the Cochrane Register of Controlled Trials (CENTRAL, The Cochrane Library, which includes Cochrane Back Review Group Trials Register; Issue 1 of 12, January 2015);

- $\quad$ MEDLINE (Ovid SP, 1946 to February week 2 2015);

- $\quad$ MEDLINE In-Process \& Other Non-Indexed Citations (Ovid SP, 13 February 2015);

- $\quad$ EMBASE (Ovid SP, 1980 to week 7 2015);

- Cumulative Index to Nursing and Allied Health Literature (CINAHL; EBSCO, 1981 to 18 February 2015);

- $\quad$ PsycINFO (Ovid SP, 2002 to February week 2 2015);

- Physiotherapy Evidence Database (PEDro);

- Cochrane Back Review Group Trials Register (Reference Manager and Cochrane Register of Studies (CRS));

- ClinicalTrials.gov;

- $\quad$ World Health Organization (WHO) International Clinical Trials Registry Platform (WHO ICTRP);

- $\quad$ PubMed.

As with the original review, we used the search strategies recommended by the Cochrane Back Review Group for the identification of RCTs [54], and adapted them to include cohort studies. The Cochrane Back Review Group Trials Search Co-ordinator developed the strategies and used a combination of controlled vocabulary 
terms (e.g. MeSH terms) and keywords to describe methodology, disorders, and treatment. These methods were consistent with the Chapter 6 of the Cochrane Handbook for Systematic Reviews of Interventions [55]

. Appendix 1, Appendix 2, and Appendix 3 show the strategies for each database.

\section{Searching other resources}

We also included the following strategies:

- $\quad$ reference lists of all relevant papers;

- main electronic sources of ongoing trials (National Research Register, meta-Register of Controlled Trials; Clinical Trials);

- grey literature, including conference proceedings, PhD theses, and unpublished work conducted by manufacturers that were likely to contain trials relevant to the review;

- contacted investigators and authors in this field for information on unpublished or incomplete trials.

All searches included non-English language studies. When considered likely to meet inclusion criteria, we translated studies published in languages other than English.

\section{Data collection and analysis}

\section{Selection of studies}

Two review authors (JBS, NC) independently evaluated the search results by reading the titles; two other review authors (TB, TM) independently reviewed the abstracts of the remaining papers. We obtained potentially relevant studies in full text and two review authors (TK, FZ) independently assessed them for inclusion. None of the papers was reviewed by any of the authors who may have written the original papers. At all stages, we resolved disagreements through discussion. The lead review author (SN) solved any persisting disagreements.

\section{Data extraction and management}

We prepared a standardized data extraction form, which we used to extract data from the included papers. Two review authors (SM, FZ) independently extracted data on the population, study characteristics, and results added to Review Manager 5.3. We discussed any disagreements, and consulted the lead review author (SN) if disagreements persisted. We summarized key findings in a narrative format and assessed for inclusion in a metaanalysis where possible.

Clinical relevance of results

The review authors assessed each trial for its clinical relevance by using the five questions outlined by Shekelle 1994 [56], and recommended by the Cochrane Back Review Group [54]. We assessed all important outcomes for each comparison. The main conclusions were clinical, because our main aim was to give clinicians state-of-theart information, according to relevant studies on this issue.

\section{Assessment of risk of bias in included studies}

We assessed the risk of bias of RCTs and controlled clinical trials (CCTs) in this review using the 12 criteria recommended by the Cochrane Back Review Group [54,55]. We used the Newcastle-Ottawa Scale (NOS scale) to assess the prospective cohort studies with a control group [57]. The NOS scale assesses three broad areas: selection bias, attrition bias, and detection bias. For each included study, each type of bias was rated as high, low, or unclear and entered into the risk of bias table (Figure 1 - 2).

Two review authors, one with methodological expertise and one with content expertise, independently assessed the risk of bias of the included studies. The review authors resolved any disagreements by discussion, including input from a third independent review author if required. Risk of bias assessment was not blinded to trial authors, institution, or journal.

\section{Measures of treatment effect}

We analysed dichotomous outcomes by calculating the risk ratio (RR) for each trial, with the uncertainty in each result expressed with $95 \%$ confidence intervals (CI). We analysed continuous outcomes by calculating the mean difference (MD) or the standardized mean difference (SMD) with 95\% CI. 


\section{Data synthesis}

Meta-analysis was not performed because the retrieved studies were too heterogeneous with regards to the study design, types of comparisons, populations included, and braces applied (elastic, rigid, very rigid). Therefore, we did not perform the pre-planned investigations of heterogeneity, sensitivity analysis excluding studies with high risk of bias, and subgroup analysis for studies at low risk of bias. We assessed the overall quality of the evidence for each outcome. We used an adapted GRADE approach, as recommended by the Cochrane Back Review Group [54]. Factors that may decrease the quality of the evidence are study design and risk of bias, inconsistency of results, indirectness (not generalizable), imprecision (sparse data), and other factors (e.g. reporting bias and publication bias). The quality of the evidence for a specific outcome was downgraded by a level, according to the performance of the studies against these five factors.

- High quality evidence: there are consistent findings among at least $75 \%$ of RCTs with low risk of bias, consistent, direct, and precise data and no known or suspected publication biases. Further research is unlikely to change either the estimate or our confidence in the results.

- Moderate quality evidence: one of the domains is not met. Further research is likely to have an important impact on our confidence in the estimate of effect and may change the estimate.

- Low quality evidence: two of the domains are not met. Further research is very likely to have an important impact on our confidence in the estimate of effect and is likely to change the estimate.

- Very low quality evidence: three of the domains are not met. We are very uncertain about the results.

- No evidence: no RCTs were identified that addressed this outcome.

\section{Results \\ Description of studies \\ Results of the search}

We found 2479 titles with the electronic search (Figure 3), 13 studies with the handsearch, and 40 titles by searching Conference Proceedings and websites. After removing duplicates, we screened 859 titles and excluded 706 based on titles and 10 after reviewing the abstracts. We retrieved 143 full texts. We excluded 135 studies, one of which because we were unable to retrieve the full paper [58]. We wrote to the principal investigators but they did not respond. Both Coillard 2012 [59] and Lusini 2013 [60] agreed to send the final versions of articles that were under review for publication. Lusini 2013 [60] has since been published. This resulted in seven included studies, two of which were reported in the original version of this review. Two studies are awaiting classification [61,62].

\section{Included studies}

Seven articles met our inclusion criteria: five were planned as RCTs [59,63-66], and two as prospective controlled trials $[60,67]$. Two RCTs failed due to very low recruitment of participants $[65,68]$.

The RCT by Weinstein 2013a [65] focused on $25^{\circ}$ to $40^{\circ}$ curves. Unfortunately, $64.7 \%$ of adolescents refused to participate and $21 \%$ of adolescents and their parents rejected randomization; other adolescents were lost for numerous reasons. The final percentage of participants that could be allocated to the randomized arm was $10.6 \%$, including $0.9 \%$ that crossed over groups. Due to this low inclusion rate, the authors extended the inclusion criteria to include adolescents with $20^{\circ}$ curves. In addition, they transformed the study into a prospective controlled trial, including a randomized arm. This study was considered both as a prospective nonrandomized study with the all sample [65], and as randomized trial considering only the sub-sample that was randomized [69].

Bunge 2010 [68] aimed to recruit adolescents and compare braces with observation only; the study failed completely during the recruitment phase; so we excluded it from further consideration.

Thus, we included four randomized controlled trials/arms [59,64,66,69], and three prospective controlled trials [60,65,67]. One controlled prospective paper had a follow-up at 16 years in a sub-group of adolescents [67].

Nachemson 1995 [67] was a worldwide collaboration including hospitals from two continents; they observed two groups of clinicians, where the first group believed in the effectiveness of treatment with a brace, and the 
second group firmly believed that a brace was ineffective and thus managed people with careful observation; two centres of this last group treated adolescents with lateral electrical surface stimulation.

Types of treatments and comparisons: Braces included elastic bands [59,66], rigid (polyethylene) [64-67,69], and very rigid (polycarbonate) thoraco-lumbo-sacral orthosis [60]. Two studies compared bracing with observation [59,65,69], one study compared bracing plus physiotherapeutic-specific scoliosis exercises versus observation [60]. One study compared rigid bracing with observation or electrical stimulation [67]. Two studies compared two different types of braces: rigid versus an elastic soft brace [66], and two different rigid braces with the same number of hours wearing the brace every day [64].

Duration of the trials: the duration was different among all included studies, with the range being between one and five years. Coillard 2012 [59] had a follow-up at five years post-randomization, Lou 2012 [64] had followup at three years, and Lusini 2013 [60] had follow-up at two to nine years. In Nachemson 1995 [67], after being treated until maturity (up to four years), a subset of all Swedish adolescents were followed up for 16 years after treatment (range 10.9 to 19.4 years), including a braced (Malmö; 41 participants) and observed (Göteborg; 65 participants) group.

Participants: 662 participants were included, of these 483 were treated with a brace, 133 observed, and 46 were prescribed a control treatment different from bracing (electrical stimulation). Studies were not completely homogeneous in terms of population characteristics. The mean age was approximately 12.5 years for all studies except Lusini 2013 [60] (mean age above 14 years). In most studies, Cobb degrees were between $20^{\circ}$ and $40^{\circ}$, apart from the studies of Coillard 2012 [59] $\left(15^{\circ}\right.$ to $\left.30^{\circ}\right)$ and Lusini 2013 [60] (greater than $45^{\circ}$ ). The two studies evaluating elastic bracing focused on low degree curves $\left(15^{\circ}\right.$ to $30^{\circ}$ [59], and $20^{\circ}$ to $30^{\circ}$ [66], while those using very rigid bracing focused on very high degree curves greater than $45^{\circ}$ [60]. Lou 2012 [64] described neither the Cobb angles nor the age of the participants.

Outcomes: of the primary outcomes considered in this review, only QoL modifications due to bracing were considered by three papers: Weinstein 2013b [69] used the PedsQL score [70,71], Nachemson 1995 [67] used the SRS22 [72,73] and the 36-item Short Form $(S F=36)$ [74,75], and Wong 2008 [66] used a purpose-designed questionnaire. All the studies focused on the secondary outcome, scoliosis progression.

Countries in which the studies were conducted: one RCT was conducted in Hong Kong [66], two in Canada [59,64], and one was a multicentre study conducted in the US and Canada [69]. One prospective cohort study was a multinational study conducted in three centres in the UK, four centres in the US, one centre in Canada, and two centres in Sweden [67]. The other prospective study was performed in Italy [60].

\section{Excluded studies}

We excluded 136 papers for the following main reasons: 45 were retrospective, 37 were prospective but without concurrent controls, and 53 were excluded for other reasons. Bunge 2008 [63] was an RCT, but was excluded from the final analysis because of the low numbers of participants that agreed to participate and be randomized.

\section{Allocation (selection bias)}

We judged the method of random sequence generation as low risk of bias in two RCTs [59,69]. Random sequence generation was unclear in the other two RCTs $[64,66]$. The allocation concealment was at low risk of bias in one RCT [59], and unclear in the remaining studies. It was at high risk of bias in the observational studies.

\section{Blinding (performance bias and detection bias)}

Neither the RCTs nor the prospective cohort studies could be blinded for participants and providers because of the type of intervention assessed (brace). The risk of detection bias was high for all the studies for subjective outcomes (e.g. QoL or disability) and low for objective outcomes (e.g. Cobb degrees or scoliosis progression). The outcome assessor was not blinded in Coillard 2012 [59], and was blinded in Weinstein 2013a [65], whereas blinding of the assessor was not reported in all other studies. Consequently, for subjective outcomes (e.g. self reported pain), we judged the risk of detection bias to be high for Coillard 2012 [59], low for Weinstein 2013a [65], and unclear in the other studies, For objective outcomes, we rated detection bias as low because they are unlikely to be biased by lack of blinding. 


\section{Incomplete outcome data (attrition bias)}

Three RCTs reported no drop-outs [64,66,69]. We judged Coillard 2012 [59] at high risk of attrition bias because there was a high rate of drop-outs and this was unbalanced between groups. In two of the prospective cohort studies, the percentage of loss at follow-up was unbalanced between groups (21\% in the experimental group and $7 \%$ in the control group in Nachemson 1995 [67]; 7.7\% in the experimental group and 44\% in the control group in Lusini 2013 [60]). However, Lusini 2013 [60] performed an intention-to-treat (ITT) analysis with worst-case analysis considering loss at follow-up as a failure for the outcome 'improvement', and as a success for the outcome 'scoliosis progression/fusion'. Consequently, we judged this study to be at low risk of attrition bias. We judged the Weinstein 2013a [65] paper at low risk of bias because there was no loss at follow-up.

\section{Selective reporting (reporting bias)}

All studies were free of selective reporting.

\section{Other potential sources of bias}

In terms of group similarity at baseline, in two RCTs, groups were similar for the main prognostic factors $[59,66]$, in one RCT, no information was reported about the baseline characteristics of participants [64]. In one prospective cohort study, the brace group had more participants with severe scoliosis, fewer participants with imbalance, and fewer participants with menarche at baseline compared with the electrical stimulation or observation-only groups [67]. Bunge 2010, Lusini 2013, and Weinstein 2013a [60,65,68] reported no information about the similarity or differences of participants at baseline.

Two of the observational studies did not adjust for the most important confounding factors. Weinstein 2013a [65] used propensity scores to reduce the effect of treatment selection bias, so we judged this study at low risk of bias due to confounding. Two studies did not report information on compliance and co-interventions. Weinstein 2013a [65] assessed compliance by temperature monitor data and self reported diary, so we judged it as being at low risk of bias due to non-compliance. The timing of outcome assessment was similar across groups in all studies.

\section{Effects of interventions}

\section{Brace versus observation (randomized controlled trials)}

Primary outcome measures

\section{Pulmonary disorders, disability, back pain, psychological issues, and cosmetic issues}

No studies assessed pulmonary disorders, disability, back pain, psychological issues, and cosmetic issues.

\section{Quality of life}

Two years' follow-up: Weinstein 2013b [69] (111 participants) found that the mean PedsQL did not differ significantly between bracing and observation (MD -2.10, 95\% CI -7.69 to 3.49).

Secondary outcome measures

\section{Progression of scoliosis}

Two years' follow-up: Weinstein 2013b [69] found the rate of success (curves remaining below 50 ${ }^{\circ}$ ) was 38/51 in the brace group and 27/65 in the observation group (RR 1.79, 95\% CI 1.29 to 2.50). The results were in favour of brace.

Three years' follow-up: Coillard 2012 [59] reported the rate of success (correction or stabilization, i.e. $5^{\circ}$ or less curve progression) as 21/26 in the brace group and 9/21 in the control group(RR 1.88, 95\% CI 1.11 to 3.20). The results were in favour of brace.

Five years' follow-up: Coillard 2012 [59] found the rate of success was 19/26 in the brace group and 12/21 in the control group (RR 1.28, 95\% CI 0.83 to 1.98). There was no significant difference between groups.

Participants with curves exceeding $\mathbf{4 5}^{\circ}$ at maturity: Coillard 2012 [59] found that 3/21 (14.3\%) participants in the control group and $3 / 26(11.5 \%)$ participants in the treated group had Cobb angles that exceeded $45^{\circ}$ at the 
end of study. Weinstein 2013b [69] found that 13/51 participants in the brace group and 38/65 in the observation group reached $50^{\circ}$ or more at the end of growth.

Participants who had undergone surgery or received a recommendation for surgery: Coillard 2012 [59] reported that $3 / 21$ (14.3\%) immature participants required surgical fusion while in the trial. The mean curve magnitude at the beginning of the treatment in this particular group was $27^{\circ}$ (range $20^{\circ}$ to $30^{\circ}$ ) and they all had a Risser sign of 0 . In the treated group, 2/26 (7.7\%) immature participants were recommended surgery during the study and 1/26 treated participant was recommended surgery after three years following the end of treatment.

\section{Adverse events}

No studies assessed adverse events.

\section{Brace versus observation or electrical stimulation (prospective cohort studies)}

Primary outcome measures

\section{Pulmonary disorders and disability}

No studies assessed pulmonary disorders, and disability.

\section{Quality of life, back pain, and psychological and cosmetic issues}

Two years' follow-up: Weinstein 2013a [65] (236 participants) reported that the mean PedsQL for all participants included in the study did not differ significantly between bracing and observation (MD 0.10, 95\% CI -3.90 to 4.10$)$.

Long-term (16 years) follow-up: the Swedish cohort of Nachemson 1995 [67] reported 16 years' follow-up with 40 participants in the observation group and 37 participants in the brace group. Using the SRS22, they found no differences between groups for each of the sub-scales and the total score (mean (SD); pain: 4.3 (0.7) with observation versus $4.4(0.6)$ with brace; $\mathrm{P}$ value $=0.94$; self image/appearance: $3.9(0.8)$ with observation versus 3.9 (0.7) with brace; $\mathrm{P}$ value $=0.98$; function/activity: 4.5 (0.5) with observation versus 4.5 (0.5) with brace; $\mathrm{P}$ value $=0.60$; mental health: $4.1(0.7)$ with observation versus $4.1(0.7)$ with brace; $\mathrm{P}$ value $=0.93$; satisfaction with management: 3.7 (1.0) with observation versus $3.8(0.9)$ with brace; $\mathrm{P}$ value $=0.45$; total score: $4.1(0.5)$ with observation versus $4.2(0.4)$ with brace; $\mathrm{P}$ value $=0.91)$.

Similarly, there were no differences using the SF-36 (mean observation versus brace; physical functioning 94.5 (95\% CI 91.9 to 97.1 ) versus 94.9 (95\% CI 92.1 to 97.1); P value $=0.80$; role physical: 93.1 (95\% CI 87.3 to 98.9) versus 91.9 (95\% CI 84.8 to 97.7); P value = 0.94; bodily pain: 75.0 (95\% CI 67.4 to 82.5 ) versus 68.1 (95\% CI 60.2 to 74.5); P value = 0.19; general health: 83.7 (95\% CI 74.6 to 88.2) versus 79.8 (95\% CI 75.1 to 83.6); $\mathrm{P}$ value $=0.15$; vitality: 69.9 (95\% CI 63.3 to 76.1 ) versus 68.2 (95\% CI 61.6 to 73.7$)$; $\mathrm{P}$ value $=0.78$; social functioning: 91.9 (95\% CI 86.7 to 97.0 ) versus 89.5 (95\% CI 83.3 to 94.6); P value $=0.34$; emotional aspects: 90.0 (95\% CI 82.5 to 97.5 ) versus 86.5 (95\% CI 76.5 to 94.6 ); $\mathrm{P}$ value $=0.79$; mental health: 83.5 (95\% CI 78.9 to 88.1) versus 81.3 (95\% CI 76.2-85.4); P value = 0.51).

Secondary outcome measures

\section{Progression of scoliosis}

Two years' follow-up: Weinstein 2013a [65] examined rate of success (curves not evolving to $50^{\circ}$ or above) among 146 braced and 96 observed participants. The rate of success was in favour of the bracing group (RR $1.50,95 \%$ CI 1.19 to 1.89$)$.

Three years' follow-up: Nachemson 1995 [67] reported that the success rates (defined as less than $6^{\circ}$ increase of the curve) were $80 \%$ (95\% CI 66\% to $88 \%$ ) for bracing, $46 \%$ (95\% CI $25 \%$ to 56\%) for observation, and 39\% (95\% CI 19\% to 59\%) for electrical stimulation. When comparing brace with observation, the results favoured the brace group (240 participants; RR 1.75, 95\% CI 1.42 to 2.16).

Four years' follow-up: Nachemson 1995 [67] reported that the success rates were 74\% (95\% CI 52\% to 84\%) for bracing, 34\% (95\% CI 16\% to 49\%) for observation, and 33\% (95\% CI 12\% to 60\%) for electrical stimulation (log-rank test $\mathrm{P}$ value $<0.0001$ ). When comparing brace with observation, the results favoured the brace group (240 participants; RR 2.22, 95\% CI 1.70 to 2.90). A worst-case analysis for the bracing group in 
which the 23 participants who dropped out from the brace arm were considered to have had failed treatment, maintained a highly significant success in preventing progression of $6^{\circ}$ or more until skeletal maturity (log-rank test $\mathrm{P}$ value $<0.0005)$.

Long-term (16 years) follow-up: Nachemson 1995 [67] found that participants braced or observed progressed more than $5^{\circ}$ (range $5^{\circ}$ to $21^{\circ}$ ). This progression meant that braced participants returned to the pre-treatment levels (31.9 $9^{\circ}$ now versus $33.0^{\circ}$ at start). Observed participants (excluding 11 who were braced and six who were fused during growth because of failure) showed an overall progression from the start of treatment of $6.4^{\circ}$ (range $5^{\circ}$ to $14^{\circ}$ ).

\section{Adverse events}

Two years' follow-up: Weinstein 2013a [65] found no difference between groups in the percentage of participants with any adverse event (RR 1.27, 95\% CI 0.96 to 1.67) and in the percentage of participants reporting back pain (which was the most common adverse event) (RR 0.72, 95\% CI 0.47 to 1.10;). One serious adverse event, a hospitalization for anxiety and depression, was reported in one participant who wore a brace. Adverse events involving the skin under the brace were reported in 12/146 (8\%) participants who wore a brace.

\section{Brace and exercise versus observation in high-degree curves (prospective cohort study)}

Primary outcome measures

\section{Pulmonary disorders, disability, back pain, psychological issues, cosmetic issues, and quality of life}

The study did not assess pulmonary disorders, disability, back pain, psychological issues, cosmetic issues, and QoL.

Secondary outcome measures

\section{Progression of scoliosis}

Two to nine years' follow up: Lusini 2013 [60] reported that the rate of success (no progression of $5^{\circ}$ or more, no fusion, or no waiting list for fusion) was 25/33 in the brace group and 0/10 in observation group in the perprotocol analysis (RR 15.21, 95\% CI 1.00 to 230.23) and 31/39 in the brace group and 8/18 in the observation group in the ITT analysis (RR 1.79, 95\% CI 1.04 to 3.07). The results were in favour of brace.

\section{Adverse events}

The study did not assess adverse events.

\section{Smart brace versus standard rigid brace (randomized controlled trial)}

Primary outcome measures

Pulmonary disorders, disability, back pain, psychological issues, cosmetic issues, and quality of life The study did not assess pulmonary disorders, disability, back pain, psychological issues, cosmetic issues, and QoL.

Secondary outcome measures

\section{Progression of scoliosis}

Lou 2012 [64] (12 participants) found no significant difference between the Smart brace and the standard rigid brace. The Cobb angles (mean $\pm \mathrm{SD}$ ) were: pre-brace $33 \pm 6^{\circ}$ with Smart brace versus $33 \pm 6^{\circ}$ with standard rigid brace; in brace: $20 \pm 5^{\circ}$ with Smart brace versus $21 \pm 4^{\circ}$ with standard rigid brace; three years after: $35 \pm 7^{\circ}$ with Smart brace versus $38 \pm 9^{\circ}$ with standard rigid brace. The in-brace correction (\% of initial Cobb angle) was $38 \pm 3 \%$ with Smart brace versus $36 \pm 5 \%$ with standard rigid brace.

Five years' follow-up: risk of progression (mean \pm SD): $60.2 \pm 27 \%$ with Smart versus $63.4 \pm 27 \%$ with standard rigid brace. At the end of treatment, the Cobb angle progressed by (mean \pm SD) $2.2 \pm 1.2^{\circ}$ with Smartbrace versus $4.8 \pm 8^{\circ}$ with standard rigid brace.

\section{Adverse events}

The study did not assess adverse events. 


\section{Compliance}

The participants in the Smart brace group were more likely to wear their brace at the prescribed level during day time activity compared with the standard rigid group (67\% with Smart brace versus 54\% with standard rigid brace).

\section{Rigid brace versus elastic brace (randomized controlled trial)}

Primary outcome measures

\section{Pulmonary disorders, disability, back pain, psychological issues, and cosmetic issues}

The study did not assess pulmonary disorders, disability, back pain, psychological issues, and cosmetic issues.

\section{Quality of life}

While the rigid brace caused significantly more problems with heat (85\% with rigid brace versus $27 \%$ with elastic brace), as well as difficulties with donning and doffing, the participants using the elastic braces had difficulties with toileting [66] (Wong 2008).

Secondary outcome measures

\section{Progression of scoliosis}

Four years' follow-up: Wong 2008 [66] found that, in participants with $20^{\circ}$ to $30^{\circ} \mathrm{Cobb}$ angle before skeletal maturity, a rigid brace showed better results than an elastic brace (SpineCor) (risk of success defined as no progression more than $5^{\circ}$ : RR $1.40,95 \%$ CI 1.03 to 1.89 ).

\section{Adverse events}

Wong 2008 [66] did not assess adverse events.

\section{Discussion}

\section{Summary of main results}

Despite a comprehensive search of published and unpublished literature, we found only seven studies (one failed), which included 662 participants.

We did not find any results on pulmonary disorders and disability. There was moderate quality evidence from one small RCT (111 participants) that QoL did not differ significantly between rigid bracing and observation [69]; QoL, back pain, and psychological and cosmetic issues did not change in the long term (16 years) (very low quality evidence) [67]. All included papers were consistent in showing that bracing prevented progression (secondary outcome): rigid bracing in $20^{\circ} 40^{\circ}$ curves (moderate quality evidence) [65,67,69], elastic bracing in $15^{\circ}$ to $30^{\circ}$ curves (low quality evidence) [59], very rigid bracing in high degree curves above $45^{\circ}$ (very low quality evidence) [60]; rigid was more successful than elastic bracing (low quality evidence) [66], and a pad pressure control system did not increase results (very low quality evidence) [64]. Nevertheless, due to the strength of evidence (from low to very low quality), further research is very likely to have an important impact on our confidence in the estimate of effect and is likely to change the estimate.

No specific harms have been reported. The high rate of failure of RCTs demonstrated the huge difficulties in performing RCTs in a field where parents reject randomization of their children: this questions the possibility of consistently increasing the strength of the actual evidence.

\section{Overall completeness and applicability of evidence}

The current evidence about brace treatment for AIS is of low to very low quality. Until now, four RCTs have been performed, two comparing two types of braces [64,66], and two comparing braces versus observation [59,69]. In Coillard 2012 [59] and Wong 2008 [66], participants had a range of pathology below the most frequent indications for bracing [1], $15-30^{\circ}$ [59], and $20^{\circ}$ to $30^{\circ}$ [66]. On the contrary, in the classical range of $25^{\circ}$ to $40^{\circ}$ curves $[1,31]$ the implementation of RCTs is challenging. The members of one of the main scientific societies in the field, the SRS, which consists mainly of orthopaedic surgeons, were found to be in equipoise on bracing [51], and were able to plan an RCT [69]; conversely, members of the second main society, the conservative experts of SOSORT, rejected the possibility of performing an RCT [1,76,77]; they found this 
possibility comparable to an RCT on parachutes [78]. Despite these professional positions, the strongest argument against the possibility of performing RCTs comes from the reality that most parents (70\% to $80 \%$ of cases) will not allow their children to be randomized. This was the main reason for failure of the two best efforts performed in recent years [63,65,77]. In fact, while the Dutch RCT failed completely [68], the US trial [65], financed with more than USD 5 million by the US Government through the 'National Institute of Arthritis and Musculoskeletal and Skin Diseases', has finally been changed from an RCT to a CCT [65]. In 2013, the ethical committee requested that the study be stopped due to the evident success of bracing [65], and for this reason, it was also possible to report the RCT data. Therefore, the probability of new, future RCTs of bracing versus observation is low. Clinicians in this field will rely on the current low quality evidence for many years to come. Bunge, the main Dutch researcher (an epidemiologist) concluded, "it is harder to perform a RCT that abolishes or postpones a treatment than a RCT that adds a new treatment" [68]. Nevertheless, RCTs comparing different types or designs of braces $[64,66]$, or different approaches have already been done and will presumably be performed in the future.

Apart from the research design used by Alf Nachemson [67], the SRS Bracing Committee proposed another possible study design to address the methodological criteria for bracing studies [31]. Compliance and the standard of bracing should also be considered [76,79]. In fact, the wide range of results in brace studies [50] usually leads to a discussion on the methodology of the study and the type of brace used, but the quality of bracing and participants' management should also be considered [76,79]. These have been addressed by the Society on Scoliosis Orthopaedic and Rehabilitation Treatment (SOSORT) with the Guidelines on "Standards of management of idiopathic scoliosis with corrective braces in daily clinics and in clinical research" [76]. The SRS and SOSORT criteria for bracing should be considered for the methodological and management standards to be followed in future research studies, and will allow meta-analysis to be performed on solid methodological criteria.

Other fields to be explored are the importance of compliance and methods to increase compliance [80,81]; the possible usefulness of physiotherapeutic scoliosis (specific or not) exercises [1,82]; means to reduce the impact of bracing on participants, even if according to our results there is low quality evidence that it is not different from observation alone [65].

\section{Clinical relevance}

All included studies strongly mimic the clinical reality (high ecological and external validity). Two studies included only females, which reflects the fact that the majority (80\% to $90 \%$ ) of people with AIS are female [66,67]. In fact, the limit of the current evidence comes from the difficulty previously discussed in performing a classical RCT (high internal, but usually low external validity).

Generally in the literature, and specifically in the retrieved studies within this review, outcomes other than Cobb degrees are barely considered. This reflects physicians' attitudes that during growth, their focus is on avoiding or at least curbing curve progression (secondary aim) to prevent future problems of QoL, disability, back pain, etc. (primary aims). This approach comes from the fact that scoliosis is progressive during growth, and if the curves surpass $30^{\circ} \mathrm{Cobb}$ at the end of growth, the risk of health problems in adulthood increases. Consequently, results reported in this review are clinically relevant, according to the current focus in the literature on Cobb degrees as the primary outcome. Nevertheless, the lack of focus on secondary adverse effects of treatment, as well as the absence of long-term, primary outcome results (QoL, disability, pain) must be stressed and addressed in future studies.

No major risks of the intervention have been reported in the literature, apart from skin problems and anxiety [65], hot during summer with rigid bracing and difficulties in toileting with the elastic braces, that is, minor adverse effects [66].

\section{Quality of the evidence}

Overall, the quality of evidence in favour of bracing alone or bracing plus exercise compared to observation or electrical stimulation is from low to very low quality. The included studies for these comparisons were two RCTs with only 47 and 116 participants. One RCT was at high risk of attrition bias, the other trial was at unclear risk of selection bias. The other included studies were three prospective cohort studies, two of which had a high attrition rate and no adjustment for potential confounding factors. In addition, the evidence for comparisons of 
different types of braces is low: only two RCTs with very small sample size and a high or unclear risk of bias across all domains of bias.

Note that since $80 \%$ to $90 \%$ of people with AIS are female, the inclusion of one study of only females was not considered to be a source of indirectness [66,67].

\section{Potential biases in the review process}

The strength of the review is the extensive and comprehensive searches conducted, including many different sources in many languages. Another strength is its high ecological validity, due to the real-life situations considered in the studies. The main weakness of the review is the absence of strong studies in this field that do not make it possible to reach firm conclusions. Nevertheless, results among the studies included are fairly coherent. Two authors of this review were also authors of one of the primary studies [60]; this paper was evaluated by the other review authors.

\section{Agreements and disagreements with other studies or reviews}

The previous Cochrane review was based on two studies only [53,83]. In recent years, a number of welldesigned studies have been conducted, and as a whole, the current evidence is much stronger than that presented in the original review.

One "evidence-based review" looked at entirely different outcomes from those considered here: the "rate of surgery" (failure of treatment) in braced groups ranged between $1.4 \%$ and $41 \%$ [50]. This paper was based on retrospective comparative studies, and on retrospective and prospective case series results, all of which we excluded from the current review. Furthermore, only papers in English were considered, while those adding exercises to bracing were excluded. It was not possible to obtain a good uniformity of methods and outcomes among papers, even if sub-group analysis was attempted. These problems could be overcome following the SRS criteria for bracing studies [31]. Moreover, excluding papers that add exercises to bracing should not be done in the future, because, according to SOSORT criteria [76], this is a management criterion to increase compliance. In fact, papers including exercises report very low surgery rates (2\% to $7 \%$ for efficacy analysis, $10 \%$ to $14 \%$ for worst -case analysis), comparable to the best results in the bracing papers reported above [24,84-87].

\section{Authors' conclusions \\ Implications for practice}

Due to the important clinical differences among the studies, it was not possible to perform a meta-analysis. We found no studies reporting pulmonary disorders and disability; one study showed that bracing did not change quality of life (QoL) during treatment (moderate quality evidence); QoL, back pain, and psychological and cosmetic issues did not change in the long term (16 years) (very low quality). All included papers were consistent in showing that bracing avoided progression (secondary outcome). Due to the strength of evidence (from moderate to very low, owing to the methodological quality of the studies), a good estimate of the effect remains uncertain. The high rate of failure of randomized controlled trials (RCTs) demonstrates the huge difficulties in performing RCTs in a field where parents reject randomization of their children: this questions the possibility of consistently increasing the strength of the actual evidence.

\section{Implications for research}

Due to the difficulties in performing RCTs in this field, "expertise-based" trials, where people are randomized to centres acting according to their preferred protocols, are a possible option. Together with controlled prospective trials, another option is studies conducted according to the SRS [31] and SOSORT [76] criteria for bracing to allow comparability, such as prospective multicentre cohort studies or prospective case series of participants treated and not treated. Other similar criteria for different populations would be important to allow future metastudies to be performed.

Moreover, any future study should significantly widen their focus on participant outcomes (not just radiographic outcomes of scoliosis progression) as well as adverse effects, so that balanced conclusions may be generated. Other fields to be explored are the importance of compliance and methods to increase compliance; the possible usefulness of physiotherapeutic exercises as well as means to reduce the impact of bracing on participants. 


\section{Acknowledgements}

We wish to thank all the Cochrane Back Group Editors, and particularly Vicki Pennick (first edition), Teresa Marin (second edition), and Rachel Couban, for their work and continuous help. Specifically, Rachel Couban who performed all the electronic searches. 


\section{References}

[1] Negrini S, Aulisa AG, Aulisa L, Circo AB, de Mauroy JC, Durmala J, et al. 2011 SOSORT guidelines: Orthopaedic and Rehabilitation treatment of idiopathic scoliosis during growth. Scoliosis 2012;7:3. doi:10.1186/1748-7161-7-3.

[2] Hresko MT. Clinical practice. Idiopathic scoliosis in adolescents. N Engl J Med 2013;368:834-41. doi:10.1056/NEJMcp1209063.

[3] Grivas TB, Vasiliadis E, Mouzakis V, Mihas C, Koufopoulos G. Association between adolescent idiopathic scoliosis prevalence and age at menarche in different geographic latitudes. Scoliosis 2006;1:9. doi:10.1186/1748-7161-1-9.

[4] Lonstein JE. Scoliosis: surgical versus nonsurgical treatment. Clin Orthop 2006;443:248-59. doi:10.1097/01.blo.0000198725.54891.73.

[5] Parent S, Newton PO, Wenger DR. Adolescent idiopathic scoliosis: etiology, anatomy, natural history, and bracing. Instr Course Lect 2005;54:529-36.

[6] Freidel K, Petermann F, Reichel D, Steiner A, Warschburger P, Weiss HR. Quality of life in women with idiopathic scoliosis. Spine 2002;27:E87-91.

[7] Freidel K, Reichel D, Steiner A, Warschburger P, Petermann F, Weiss H-R. Idiopathic scoliosis and quality of life. Stud Health Technol Inform 2002;88:24-9.

[8] Danielsson AJ, Nachemson AL. Radiologic findings and curve progression 22 years after treatment for adolescent idiopathic scoliosis: comparison of brace and surgical treatment with matching control group of straight individuals. Spine 2001;26:516-25.

[9] Negrini S, Grivas TB, Kotwicki T, Maruyama T, Rigo M, Weiss HR, et al. Why do we treat adolescent idiopathic scoliosis? What we want to obtain and to avoid for our patients. SOSORT 2005 Consensus paper. Scoliosis 2006;1:4. doi:10.1186/1748-7161-1-4.

[10] Weinstein SL, Dolan LA, Spratt KF, Peterson KK, Spoonamore MJ, Ponseti IV. Health and function of patients with untreated idiopathic scoliosis: a 50-year natural history study. JAMA J Am Med Assoc 2003;289:559-67.

[11] Danielsson AJ, Nachemson AL. Back pain and function 23 years after fusion for adolescent idiopathic scoliosis: a case-control study-part II. Spine 2003;28:E373-83. doi:10.1097/01.BRS.0000084267.41183.75.

[12] Danielsson AJ, Nachemson AL. Back pain and function 22 years after brace treatment for adolescent idiopathic scoliosis: a case-control study-part I. Spine 2003;28:2078-85; discussion 2086.

doi:10.1097/01.BRS.0000084268.77805.6F.

[13] Grivas TB, Vasiliadis ES, Rodopoulos G, Bardakos N. The role of the intervertebral disc in correction of scoliotic curves. A theoretical model of idiopathic scoliosis pathogenesis. Stud Health Technol Inform 2008;140:33-6.

[14] Mayo NE, Goldberg MS, Poitras B, Scott S, Hanley J. The Ste-Justine Adolescent Idiopathic Scoliosis Cohort Study. Part III: Back pain. Spine 1994;19:1573-81. 
[15] Pehrsson K, Larsson S, Oden A, Nachemson A. Long-term follow-up of patients with untreated scoliosis. A study of mortality, causes of death, and symptoms. Spine 1992;17:1091-6.

[16] Pehrsson K, Danielsson A, Nachemson A. Pulmonary function in adolescent idiopathic scoliosis: a 25 year follow up after surgery or start of brace treatment. Thorax 2001;56:388-93.

[17] Vasiliadis E, Grivas TB. Quality of life after conservative treatment of adolescent idiopathic scoliosis. Stud Health Technol Inform 2008;135:409-13.

[18] Negrini S, Carabalona R. Social acceptability of treatments for adolescent idiopathic scoliosis: a crosssectional study. Scoliosis 2006;1:14. doi:10.1186/1748-7161-1-14.

[19] Fusco C, Zaina F, Atanasio S, Romano M, Negrini A, Negrini S. Physical exercises in the treatment of adolescent idiopathic scoliosis: An updated systematic review. Physiother Theory Pract 2011;27:80-114. doi:10.3109/09593985.2010.533342.

[20] Lenssinck M-LB, Frijlink AC, Berger MY, Bierman-Zeinstra SMA, Verkerk K, Verhagen AP. Effect of bracing and other conservative interventions in the treatment of idiopathic scoliosis in adolescents: a systematic review of clinical trials. Phys Ther 2005;85:1329-39.

[21] Negrini S, Antonini G, Carabalona R, Minozzi S. Physical exercises as a treatment for adolescent idiopathic scoliosis. A systematic review. Pediatr Rehabil 2003;6:227-35. doi:10.1080/13638490310001636781.

[22] Negrini S, Aulisa L, Ferraro C, Fraschini P, Masiero S, Simonazzi P, et al. Italian guidelines on rehabilitation treatment of adolescents with scoliosis or other spinal deformities. Eur Medicophysica 2005;41:183-201.

[23] Negrini S, Fusco C, Minozzi S, Atanasio S, Zaina F, Romano M. Exercises reduce the progression rate of adolescent idiopathic scoliosis: results of a comprehensive systematic review of the literature. Disabil Rehabil 2008;30:772-85. doi:10.1080/09638280801889568.

[24] Negrini S, Atanasio S, Fusco C, Zaina F. Effectiveness of complete conservative treatment for adolescent idiopathic scoliosis (bracing and exercises) based on SOSORT management criteria: results according to the SRS criteria for bracing studies - SOSORT Award 2009 Winner. Scoliosis 2009;4:19. doi:10.1186/17487161-4-19.

[25] Rigo M, Negrini S, Weiss HR, Grivas TB, Maruyama T, Kotwicki T, et al. "SOSORT consensus paper on brace action: TLSO biomechanics of correction (investigating the rationale for force vector selection)." Scoliosis 2006;1:11. doi:10.1186/1748-7161-1-11.

[26] Romano M, Negrini S. Manual therapy as a conservative treatment for adolescent idiopathic scoliosis: a systematic review. Scoliosis 2008;3:2. doi:10.1186/1748-7161-3-2.

[27] Romano M, Minozzi S, Bettany-Saltikov J, Zaina F, Chockalingam N, Kotwicki T, et al. Exercises for adolescent idiopathic scoliosis. Cochrane Database Syst Rev 2012;8:CD007837.

doi:10.1002/14651858.CD007837.pub2.

[28] Romano M, Minozzi S, Zaina F, Saltikov JB, Chockalingam N, Kotwicki T, et al. Exercises for adolescent idiopathic scoliosis: a Cochrane systematic review. Spine 2013;38:E883-93.

doi:10.1097/BRS.0b013e31829459f8. 
[29] Rowe DE, Bernstein SM, Riddick MF, Adler F, Emans JB, Gardner-Bonneau D. A Meta-Analysis of the Efficacy of Non-Operative Treatments for Idiopathic Scoliosis*†. J Bone Jt Surg 1997;79:664-74.

[30] Coillard C, Leroux MA, Zabjek KF, Rivard CH. SpineCor--a non-rigid brace for the treatment of idiopathic scoliosis: post-treatment results. Eur Spine J Off Publ Eur Spine Soc Eur Spinal Deform Soc Eur Sect Cerv Spine Res Soc 2003;12:141-8. doi:10.1007/s00586-002-0467-x.

[31] Richards BS, Bernstein RM, D’Amato CR, Thompson GH. Standardization of criteria for adolescent idiopathic scoliosis brace studies: SRS Committee on Bracing and Nonoperative Management. Spine 2005;30:2068-75; discussion 2076-7.

[32] Katz DE, Durrani AA. Factors that influence outcome in bracing large curves in patients with adolescent idiopathic scoliosis. Spine 2001;26:2354-61.

[33] Landauer F, Wimmer C, Behensky H. Estimating the final outcome of brace treatment for idiopathic thoracic scoliosis at 6-month follow-up. Pediatr Rehabil 2003;6:201-7. doi:10.1080/13638490310001636817.

[34] Rahman T, Bowen JR, Takemitsu M, Scott C. The association between brace compliance and outcome for patients with idiopathic scoliosis. J Pediatr Orthop 2005;25:420-2.

[35] SRS Bracing Manual | Scoliosis Research Society n.d. http://www.srs.org/professionals/onlineeducation-and-resources/srs-bracing-manual (accessed May 5, 2016).

[36] Climent JM, Sánchez J. Impact of the type of brace on the quality of life of Adolescents with Spine Deformities. Spine 1999;24:1903-8.

[37] Noonan KJ, Dolan LA, Jacobson WC, Weinstein SL. Long-term psychosocial characteristics of patients treated for idiopathic scoliosis. J Pediatr Orthop 1997;17:712-7.

[38] Odermatt D, Mathieu PA, Beauséjour M, Labelle H, Aubin CE. Electromyography of scoliotic patients treated with a brace. J Orthop Res Off Publ Orthop Res Soc 2003;21:931-6. doi:10.1016/S0736-0266(03)00038$\mathrm{X}$.

[39] Ugwonali OF, Lomas G, Choe JC, Hyman JE, Lee FY, Vitale MG, et al. Effect of bracing on the quality of life of adolescents with idiopathic scoliosis. Spine J Off J North Am Spine Soc 2004;4:254-60.

doi:10.1016/j.spinee.2003.12.001.

[40] Vasiliadis E, Grivas TB, Savvidou O, Triantafyllopoulos G. The influence of brace on quality of life of adolescents with idiopathic scoliosis. Stud Health Technol Inform 2006;123:352-6.

[41] Castro FP. Adolescent idiopathic scoliosis, bracing, and the Hueter-Volkmann principle. Spine J Off J North Am Spine Soc 2003;3:180-5.

[42] Coillard C, Leroux MA, Badeaux J, Rivard CH. SPINECOR: a new therapeutic approach for idiopathic scoliosis. Stud Health Technol Inform 2002;88:215-7.

[43] Lupparelli S, Pola E, Pitta L, Mazza O, De Santis V, Aulisa L. Biomechanical factors affecting progression of structural scoliotic curves of the spine. Stud Health Technol Inform 2002;91:81-5. 
[44] Negrini S, Marchini G. Efficacy of the symmetric, patient-oriented, rigid, three-dimensional, active (SPoRT) concept of bracing for scoliosis: a prospective study of the Sforzesco versus Lyon brace. Eur Medicophysica 2007;43:171-81; discussion 183-4.

[45] Smania N, Picelli A, Romano M, Negrini S. Neurophysiological basis of rehabilitation of adolescent idiopathic scoliosis. Disabil Rehabil 2008;30:763-71. doi:10.1080/17483100801921311.

[46] Stokes IAF, Burwell RG, Dangerfield PH, IBSE. Biomechanical spinal growth modulation and progressive adolescent scoliosis--a test of the "vicious cycle" pathogenetic hypothesis: summary of an electronic focus group debate of the IBSE. Scoliosis 2006;1:16. doi:10.1186/1748-7161-1-16.

[47] Altaf F, Gibson A, Dannawi Z, Noordeen H. Adolescent idiopathic scoliosis. BMJ 2013;346:f2508.

[48] Dickson RA. Spinal deformity--adolescent idiopathic scoliosis. Nonoperative treatment. Spine 1999;24:2601-6.

[49] Dickson RA, Weinstein SL. Bracing (and screening)--yes or no? J Bone Joint Surg Br 1999;81:193-8.

[50] Dolan LA, Weinstein SL. Surgical rates after observation and bracing for adolescent idiopathic scoliosis: an evidence-based review. Spine 2007;32:S91-100. doi:10.1097/BRS.0b013e318134ead9.

[51] Dolan LA, Donnelly MJ, Spratt KF, Weinstein SL. Professional opinion concerning the effectiveness of bracing relative to observation in adolescent idiopathic scoliosis. J Pediatr Orthop 2007;27:270-6. doi:10.1097/01.bpb.0000248579.11864.47.

[52] Goldberg CJ, Dowling FE, Hall JE, Emans JB. A statistical comparison between natural history of idiopathic scoliosis and brace treatment in skeletally immature adolescent girls. Spine 1993;18:902-8.

[53] Negrini S, Minozzi S, Bettany-Saltikov J, Zaina F, Chockalingam N, Grivas TB, et al. Braces for idiopathic scoliosis in adolescents. Cochrane Database Syst Rev 2010:CD006850.

doi:10.1002/14651858.CD006850.pub2.

[54] Furlan AD, Pennick V, Bombardier C, van Tulder M, Editorial Board, Cochrane Back Review Group. 2009 updated method guidelines for systematic reviews in the Cochrane Back Review Group. Spine 2009;34:1929-41. doi:10.1097/BRS.0b013e3181b1c99f.

[55] Higgins, JPT, Green, S. Cochrane Handbook for Systematic Reviews of Interventions Version 5.1.0. The Cochrane Collaboration; 2011.

[56] Shekelle PG, Andersson G, Bombardier C, Cherkin D, Deyo R, Keller R, et al. A brief introduction to the critical reading of the clinical literature. Spine 1994;19:2028S - 2031S.

[57] Wells GA. The Newcastle-Ottawa Scale (NOS) for assessing the quality of nonrandomised studies in meta-analyses 2008. http://www.ohri.ca/programs/clinical_epidemiology/oxford.asp (accessed May 5, 2016).

[58] Wessberg P, Rune H, Anders N. Time providence bracing compared to fulltime Boston bracing in adolescent idiopathic Scoliosis. A prospective randomized study. Spine Affil Soc Meet Abstr 2011.

[59] Coillard C, Circo AB, Rivard CH. A Prospective Randomized Controlled Trial of the Natural History of Idiopathic Scoliosis versus treatment with the Spinecor brace. Sosort Award 2011 Winner. Eur J Phys Rehabil Med 2014;50:479-87. 
[60] Lusini M, Donzelli S, Minnella S, Zaina F, Negrini S. Brace treatment is effective in idiopathic scoliosis over 45: an observational prospective cohort controlled study. Spine J 2013. doi:10.1016/j.spinee.2013.11.040.

[61] Guo J, Lam TP, Wong MS, Ng BKW, Lee KM, Liu KL, et al. A prospective randomized controlled study on the treatment outcome of SpineCor brace versus rigid brace for adolescent idiopathic scoliosis with follow-up according to the SRS standardized criteria. Eur Spine J Off Publ Eur Spine Soc Eur Spinal Deform Soc Eur Sect Cerv Spine Res Soc 2013. doi:10.1007/s00586-013-3146-1.

[62] Wiemann JM, Shah SA, Price CT. Nighttime bracing versus observation for early adolescent idiopathic scoliosis. J Pediatr Orthop 2014;34:603-6. doi:10.1097/BPO.0000000000000221.

[63] Bunge EM, de Koning HJ, brace trial group. Bracing patients with idiopathic scoliosis: design of the Dutch randomized controlled treatment trial. BMC Musculoskelet Disord 2008;9:57. doi:10.1186/1471-2474-957.

[64] Lou E, Hill D, Raso J, Donauer A, Moreau M, Mahood J, et al. Smart brace versus standard rigid brace for the treatment of scoliosis: a pilot study. Stud Health Technol Inform 2012;176:338-41.

[65] Weinstein SL, Dolan LA, Wright JG, Dobbs MB. Design of the Bracing in Adolescent Idiopathic Scoliosis Trial (BrAIST). Spine 2013;38:1832-41. doi:10.1097/01.brs.0000435048.23726.3e.

[66] Wong MS, Cheng JCY, Lam TP, Ng BKW, Sin SW, Lee-Shum SLF, et al. The effect of rigid versus flexible spinal orthosis on the clinical efficacy and acceptance of the patients with adolescent idiopathic scoliosis. Spine 2008;33:1360-5. doi:10.1097/BRS.0b013e31817329d9.

[67] Nachemson AL, Peterson LE. Effectiveness of treatment with a brace in girls who have adolescent idiopathic scoliosis. A prospective, controlled study based on data from the Brace Study of the Scoliosis Research Society. J Bone Joint Surg Am 1995;77:815-22.

[68] Bunge EM, Habbema JDF, de Koning HJ. A randomised controlled trial on the effectiveness of bracing patients with idiopathic scoliosis: failure to include patients and lessons to be learnt. Eur Spine J Off Publ Eur Spine Soc Eur Spinal Deform Soc Eur Sect Cerv Spine Res Soc 2010;19:747-53. doi:10.1007/s00586-010-13376.

[69] Weinstein SL, Dolan LA, Wright JG, Dobbs MB. Effects of Bracing in Adolescents with Idiopathic Scoliosis. N Engl J Med 2013;369:1512-21. doi:10.1056/NEJMoa1307337.

[70] Varni JW, Seid M, Kurtin PS. PedsQL 4.0: reliability and validity of the Pediatric Quality of Life Inventory version 4.0 generic core scales in healthy and patient populations. Med Care 2001;39:800-12.

[71] Varni JW, Burwinkle TM, Seid M, Skarr D. The PedsQL 4.0 as a pediatric population health measure: feasibility, reliability, and validity. Ambul Pediatr Off J Ambul Pediatr Assoc 2003;3:329-41.

[72] Asher M, Min Lai S, Burton D, Manna B. Discrimination validity of the scoliosis research society-22 patient questionnaire: relationship to idiopathic scoliosis curve pattern and curve size. Spine 2003;28:74-8. doi:10.1097/01.BRS.0000047636.95839.F5.

[73] Asher M, Min Lai S, Burton D, Manna B. The reliability and concurrent validity of the scoliosis research society-22 patient questionnaire for idiopathic scoliosis. Spine 2003;28:63-9.

doi:10.1097/01.BRS.0000047634.95839.67. 
[74] Ware JE, Sherbourne CD. The MOS 36-item short-form health survey (SF-36). I. Conceptual framework and item selection. Med Care 1992;30:473-83.

[75] Wiklund I, Karlberg J. Evaluation of quality of life in clinical trials. Selecting quality-of-life measures. Control Clin Trials 1991;12:204S - 216S.

[76] Negrini S, Grivas TB, Kotwicki T, Rigo M, Zaina F, international Society on Scoliosis Orthopaedic and Rehabilitation Treatment (SOSORT). Guidelines on "Standards of management of idiopathic scoliosis with corrective braces in everyday clinics and in clinical research”: SOSORT Consensus 2008. Scoliosis 2009;4:2. doi:10.1186/1748-7161-4-2.

[77] Negrini S, De Mauroy JC, Grivas TB, Knott P, Kotwicki T, Maruyama T, et al. Actual evidence in the medical approach to adolescents with idiopathic scoliosis. Eur J Phys Rehabil Med 2014;50:87-92.

[78] Smith GCS, Pell JP. Parachute use to prevent death and major trauma related to gravitational challenge: systematic review of randomised controlled trials. BMJ 2003;327:1459-61. doi:10.1136/bmj.327.7429.1459.

[79] Grivas TB. Maintaining mobility of the spine. Steps toward more effective scoliosis brace treatment to prevent the need for fusion. 2012. http://www.boneandjoint.org.uk/content/maintaining-mobilityspine\%E2\%80\%A6 (accessed May 5, 2016).

[80] Donzelli S, Zaina F, Negrini S. In defense of adolescents: They really do use braces for the hours prescribed, if good help is provided. Results from a prospective everyday clinic cohort using thermobrace. Scoliosis 2012;7:12. doi:10.1186/1748-7161-7-12.

[81] Katz DE, Herring JA, Browne RH, Kelly DM, Birch JG. Brace wear control of curve progression in adolescent idiopathic scoliosis. J Bone Joint Surg Am 2010;92:1343-52. doi:10.2106/JBJS.I.01142.

[82] Zaina F, Negrini S, Atanasio S, Fusco C, Romano M, Negrini A. Specific exercises performed in the period of brace weaning can avoid loss of correction in Adolescent Idiopathic Scoliosis (AIS) patients: Winner of SOSORT’s 2008 Award for Best Clinical Paper. Scoliosis 2009;4:8. doi:10.1186/1748-7161-4-8.

[83] Negrini S, Minozzi S, Bettany-Saltikov J, Zaina F, Chockalingam N, Grivas TB, et al. Braces for idiopathic scoliosis in adolescents. Spine 2010;35:1285-93. doi:10.1097/BRS.0b013e3181dc48f4.

[84] Maruyama T, Kitagawa T, Takeshita K, Mochizuki K, Nakamura K. Conservative treatment for adolescent idiopathic scoliosis: can it reduce the incidence of surgical treatment? Pediatr Rehabil 2003;6:215-9. doi:10.1080/13638490310001642748.

[85] Negrini S, Atanasio S, Zaina F, Romano M, Parzini S, Negrini A. End-growth results of bracing and exercises for adolescent idiopathic scoliosis. Prospective worst-case analysis. Stud Health Technol Inform 2008;135:395-408.

[86] Rigo M, Reiter C, Weiss H-R. Effect of conservative management on the prevalence of surgery in patients with adolescent idiopathic scoliosis. Pediatr Rehabil 2003;6:209-14.

doi:10.1080/13638490310001642054.

[87] Weiss H-R, Weiss G, Schaar H-J. Incidence of surgery in conservatively treated patients with scoliosis. Pediatr Rehabil 2003;6:111-8. doi:10.1080/13638490310001593446. 


\section{Figure 1}

Methodological quality summary: review authors' judgements about each methodological quality item for each included study.

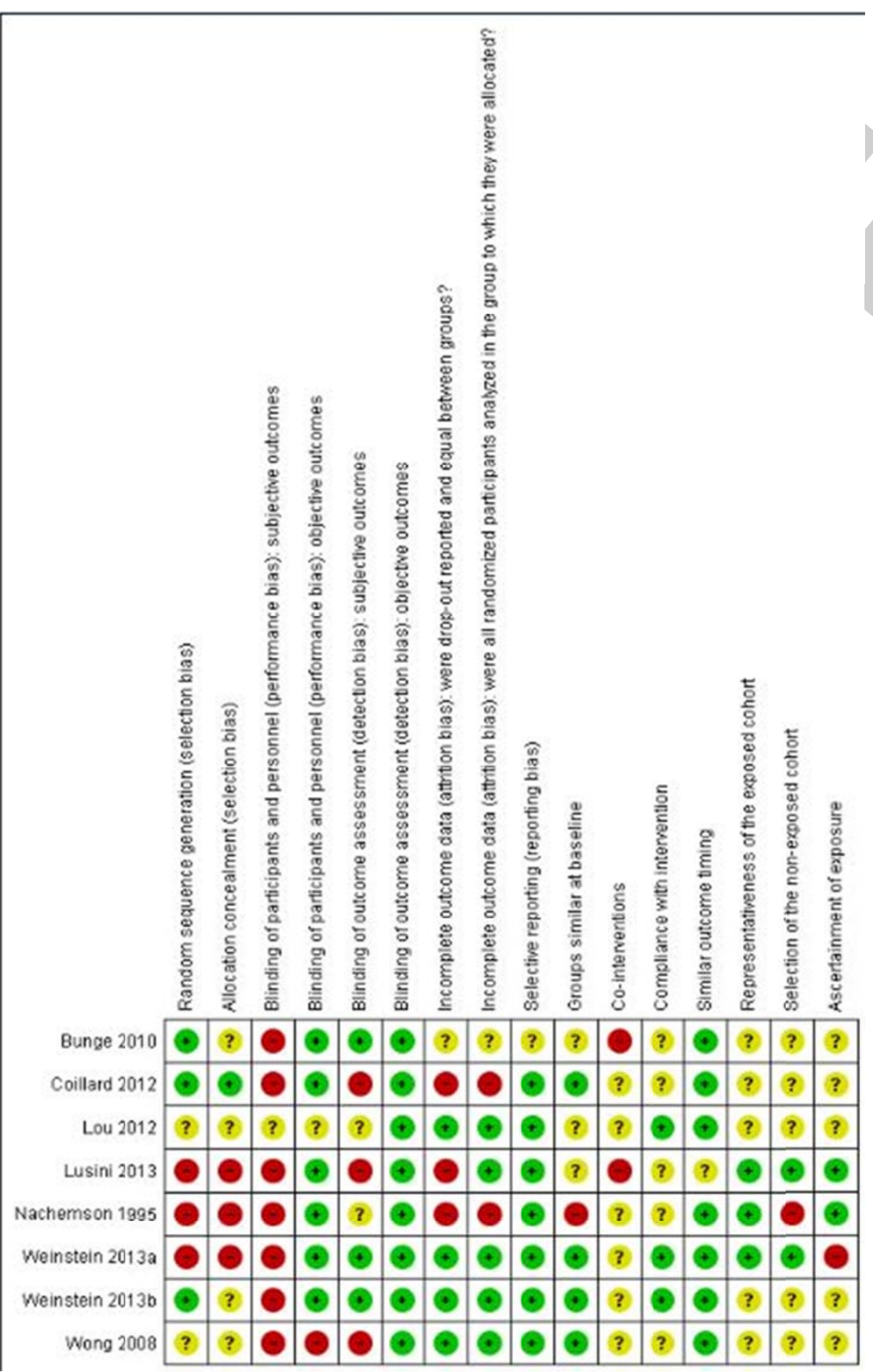

Copyright @ 2016 Wolters Kluwer Health, Inc. Unauthorized reproduction of this article is prohibited. 


\section{Figure 2}

Risk of bias graph: review authors' judgements about each risk of bias item presented as percentages across all included studies.

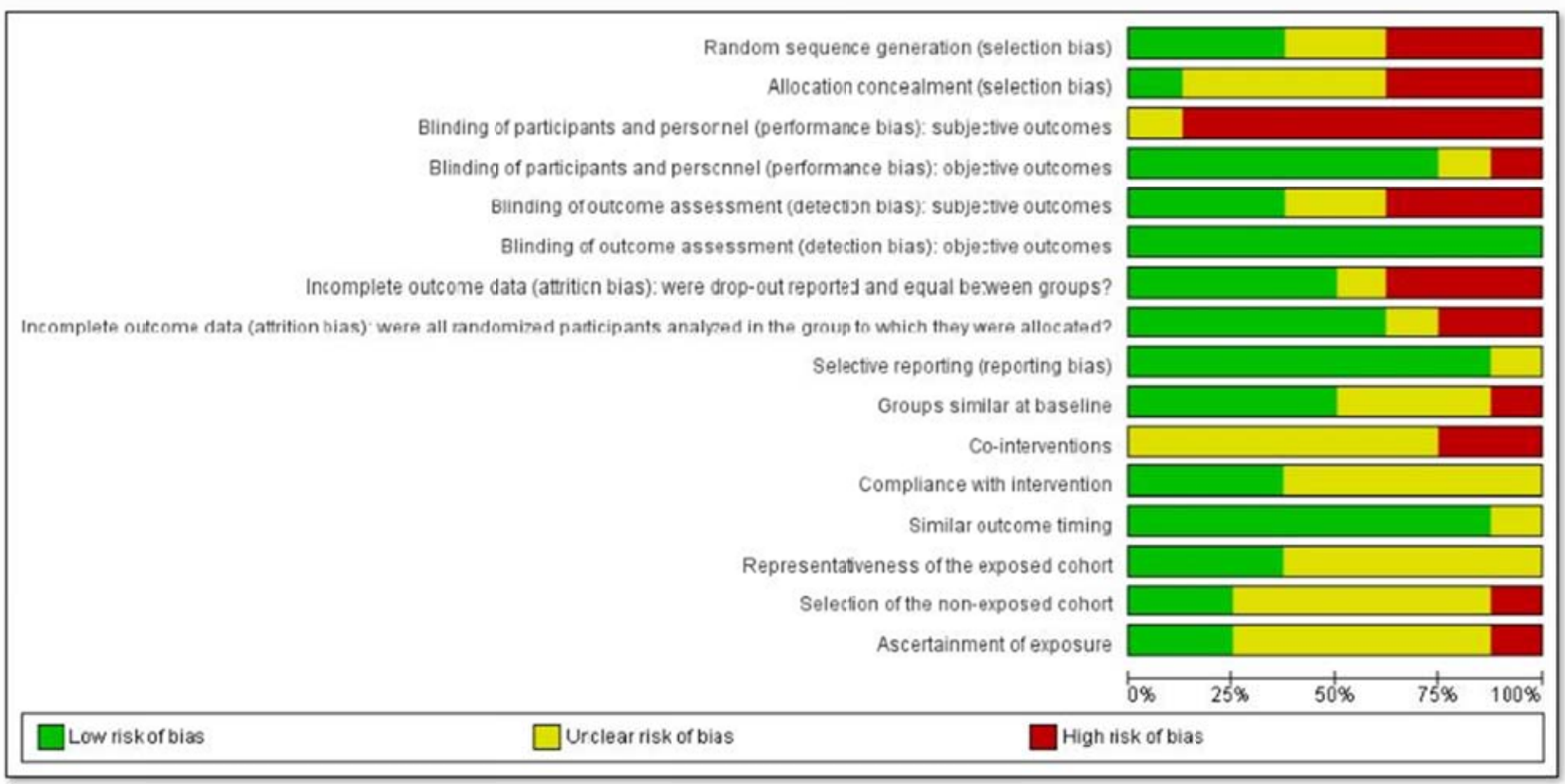




\section{Figure 3}

Study flow diagram.

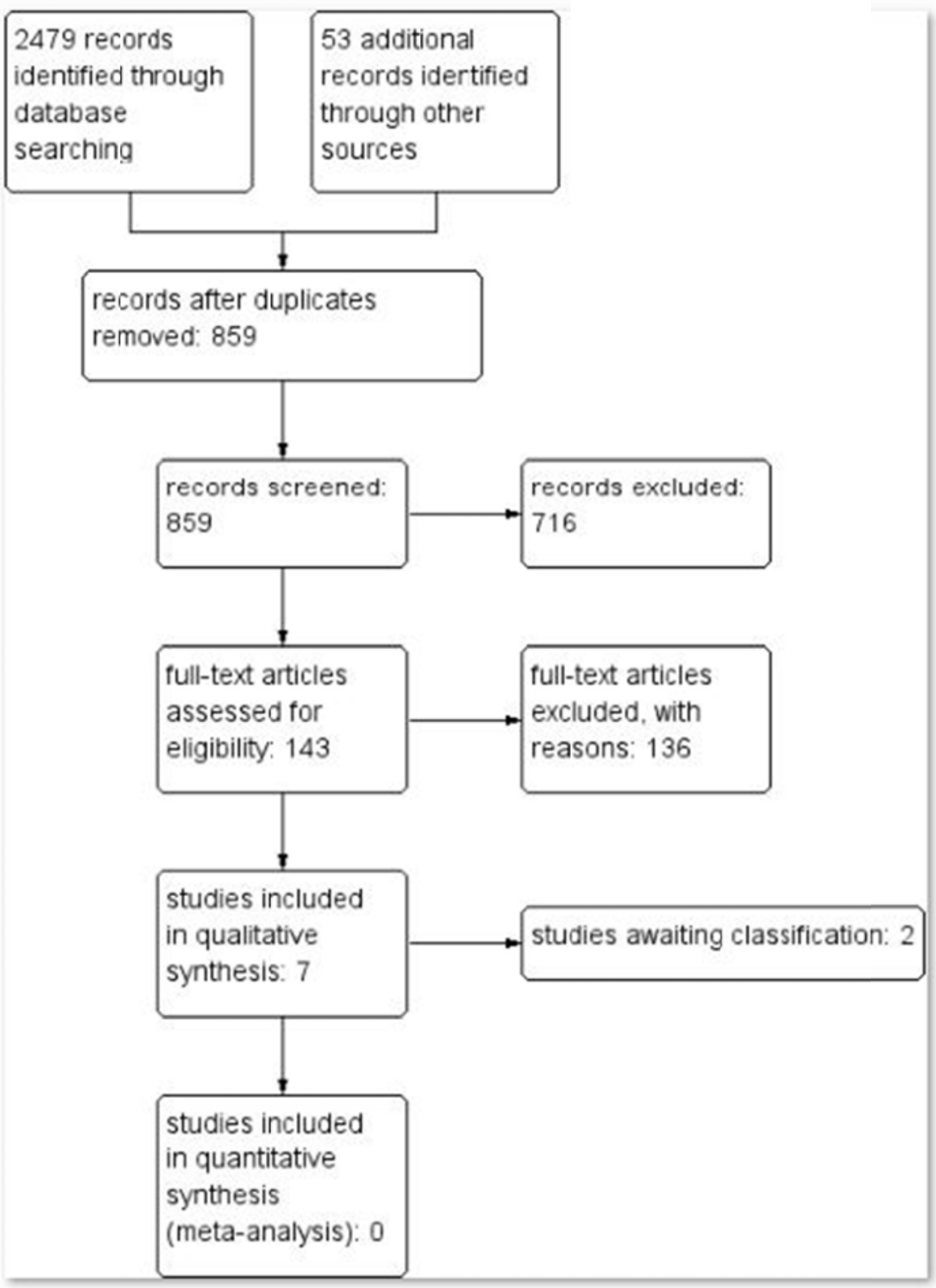

Copyright @ 2016 Wolters Kluwer Health, Inc. Unauthorized reproduction of this article is prohibited. 
1 MEDLINE and EMBASE search strategies

\section{MEDLINE and MEDLINE Non-Indexed and In-Process Citations}

Last searched 17 February 2015

1 Comparative Study/

2 exp Evaluation Studies/

3 exp Follow-Up Studies/

4 exp Prospective Studies/

5 exp Cross-Over Studies/

6 exp Epidemiologic Studies/

7 exp Case-Control Studies/

8 exp Cohort Studies/

9 exp Cross-Sectional Studies/

10 (cohort adj (study or studies)).mp.

11 cohort analy\$.mp.

12 (follow up adj (study or studies)).mp.

13 (observational adj (study or studies)).mp.

14 longitudinal.mp.

15 retrospective.mp.

16 cross sectional.mp.

17 control\$.mp.

18 prospective\$.mp.

19 volunteer.mp.

20 or/1-19

21 randomized controlled trial.pt.

22 controlled clinical trial.pt.

23 randomized.ab,ti.

24 placebo.ab,ti.

25 drug therapy.fs.

26 randomly.ab,ti.

27 trial.ab,ti.

28 groups.ab,ti.

29 or/21-27

30 (animals not (humans and animals)).sh.

3129 not 30

32 Animals/

33 Humans/

Copyright @ 2016 Wolters Kluwer Health, Inc. Unauthorized reproduction of this article is prohibited. 
3432 not (32 and 33)

\section{9 not 34}

3620 not 34

3735 or 36 or 31

38 exp Spinal Diseases/

39 exp Scoliosis/

40 scoliosis.mp.

41 or/38-40

42 exp Braces/

43 brace $\$$.mp.

44 bracing.mp.

45 exp Orthotic Devices/

46 exp Orthopedic Equipment/

47 limit 46 to $y r=" 1902$ - 1975"

48 or $/ 42-45$

4947 or 48 (

50 exp Adolescent/

51 adolescen\$.mp.

5250 or 51

5341 and 48 and 52

5437 and 53

55 limit 54 to $\mathrm{yr}=2013-2015$

56 limit 54 to ed=20131009-20150217

5755 or 56

\section{EMBASE}

Last searched 17 February 2015. For this search, the animal study filter was updated and line 51 was changed from 34 and 51 to 34 or 51. See previous strategy below.

1 exp Clinical Study/

2 exp Case Control Study/

3 exp Family Study/

4 exp Longitudinal Study/

5 exp Retrospective Study/

6 exp Prospective Study/

7 exp Cohort Analysis/

8 (cohort adj (study or studies)).mp. [mp=title, abstract, subject headings, heading word, drug trade name, original title, device manufacturer, drug manufacturer, device trade name, keyword] 
9 (case control adj (study or studies)).mp. [mp=title, abstract, subject headings, heading word, drug trade name, original title, device manufacturer, drug manufacturer, device trade name, keyword]

10 (follow up adj (study or studies)).mp. [mp=title, abstract, subject headings, heading word, drug trade name, original title, device manufacturer, drug manufacturer, device trade name, keyword]

11 (observational adj (study or studies)).mp. [mp=title, abstract, subject headings, heading word, drug trade name, original title, device manufacturer, drug manufacturer, device trade name, keyword]

12 (epidemiologic\$ adj (study or studies)).mp. [mp=title, abstract, subject headings, heading word, drug trade name, original title, device manufacturer, drug manufacturer, device trade name, keyword]

13 (cross sectional adj (study or studies)).mp. [mp=title, abstract, subject headings, heading word, drug trade name, original title, device manufacturer, drug manufacturer, device trade name, keyword]

14 exp Comparative Study/

15 evaluation study.mp.

16 follow-up study.mp. or exp Follow Up/

17 Crossover Procedure/

18 prospective\$.mp.

19 exp VOLUNTEER/

20 or/1-19

21 Clinical Article/

22 exp Clinical Study/

23 Clinical Trial/

24 Controlled Study/

25 Randomized Controlled Trial/

26 Major Clinical Study/

27 Double Blind Procedure/

28 Multicenter Study/

29 Single Blind Procedure/

30 Phase 3 Clinical Trial/

31 Phase 4 Clinical Trial/

32 crossover procedure/

33 placebo/

$34 \mathrm{or} / 21-33$

35 allocat\$.mp.

36 assign\$.mp.

37 blind\$.mp.

38 (clinic\$ adj25 (study or trial)).mp.

39 compar\$.mp.

40 control\$.mp.

41 cross?over.mp. 
42 factorial\$.mp.

43 follow?up.mp.

44 placebo\$.mp.

45 prospectiv\$.mp.

46 random\$.mp.

47 ((singl\$ or doubl\$ or trebl\$ or tripl\$) adj25 (blind\$ or mask\$)).mp.

48 trial.mp.

49 (versus or vs).mp.

50 or/35-49

5134 or 50

5220 or 51

53 exp animals/ or exp invertebrate/ or animal experiment/ or animal model/ or animal tissue/ or animal cell/ or nonhuman/

54 human/ or normal human/ or human cell/

5553 and 54

5653 not 55

5752 not 56

58 exp SPINE/

59 exp Spine Disease/

60 exp SCOLIOSIS/

61 exp Idiopathic Scoliosis/

62 scoliosis.mp.

63 or $/ 58-62$

64 exp Brace/

65 brace\$.mp.

66 bracing.mp.

67 exp ORTHOTICS/

68 exp orthopedic equipment/

69 or/64-68

70 Adolescent/

71 adolescen\#.mp.

7270 or 71

7363 and 69 and 72

7457 and 73

75 limit 74 to $y r=2013-2015$

76 limit 74 to em=201340-201507

7775 or 76

Copyright @ 2016 Wolters Kluwer Health, Inc. Unauthorized reproduction of this article is prohibited. 
Previous search strategy for 2012 and 2013

1 exp Clinical Study/

2 exp Case Control Study/

3 exp Family Study/

4 exp Longitudinal Study/

5 exp Retrospective Study/

6 exp Prospective Study/

7 exp Cohort Analysis/

8 (cohort adj (study or studies)).mp.

9 (case control adj (study or studies)).mp.

10 (follow up adj (study or studies)).mp.

11 (observational adj (study or studies)).mp.

12 (epidemiologic\$ adj (study or studies)).mp.

13 (cross sectional adj (study or studies)).mp.

14 exp Comparative Study/

15 evaluation study.mp.

16 follow-up study.mp. or exp Follow Up/

17 Crossover Procedure/

18 prospective\$.mp.

19 exp VOLUNTEER/

20 or/1-19

21 Clinical Article/

22 exp Clinical Study/

23 Clinical Trial/

24 Controlled Study/

25 Randomized Controlled Trial/

26 Major Clinical Study/

27 Double Blind Procedure/

28 Multicenter Study/

29 Single Blind Procedure/

30 Phase 3 Clinical Trial/

31 Phase 4 Clinical Trial/

32 crossover procedure/

33 placebo/

34 or/21-33

35 allocat\$.mp. 
36 assign\$.mp.

37 blind\$.mp.

38 (clinic\$ adj25 (study or trial)).mp.

39 compar\$.mp.

40 control\$.mp.

41 cross?over.mp.

42 factorial\$.mp.

43 follow?up.mp.

44 placebo\$.mp.

45 prospectiv\$.mp.

46 random\$.mp.

47 ((singl\$ or doubl\$ or trebl\$ or tripl\$) adj25 (blind\$ or mask\$)).mp.

48 trial.mp.

49 (versus or vs).mp.

50 or/35-49

5134 and 50

5220 or 51

53 Human/

54 Nonhuman/

55 exp ANIMAL/

56 Animal Experiment/

5754 or 55 or 56

5853 not 57

5952 not 57

6058 or 59

61 exp SPINE/

62 exp Spine Disease/

63 exp SCOLIOSIS/

64 exp Idiopathic Scoliosis/

65 scoliosis.mp.

66 or/61-65

67 exp Brace/

68 brace\$.mp.

69 bracing.mp.

70 exp ORTHOTICS/

71 exp orthopedic equipment/ 
72 or/67-71

73 Adolescent/

74 adolescen\#.mp.

7573 or 74

7666 and 72 and 75

7752 and 76

Copyright @ 2016 Wolters Kluwer Health, Inc. Unauthorized reproduction of this article is prohibited. 


\section{CENTRAL and CINAHL search strategies}

CENTRAL

Last searched 17 February 2015.

\#1 MeSH descriptor: [Scoliosis] this term only

\#2 scoliosis

\#3 \#1 or \#2

\#4 MeSH descriptor: [Braces] this term only

\#5 braces in Trials

\#6 bracing in Trials

\#7 \#4 or \#5 or \#6

\#8 \#3 and \#7

\#9 \#8 Publication Year from 2013 to 2015, in Trials

CINAHL

Last searched 18 February 2015.

S14 S13 Limiters - Published Date: 20131001-20150231

S13 S12 and S9 and S5

S12 S11 or S10

S11 adolescen*

S10 (MH "Adolescence+")

S9 S8 or S7 or S6

S8 "bracing*"

S7 "brace*"

S6 (MH "Orthoses+")

$\mathrm{S} 5 \mathrm{~S} 4$ or $\mathrm{S} 3$ or $\mathrm{S} 2$ or $\mathrm{S} 1$

S4 "scoliosis"

S3 (MH "Scoliosis")

S2 (MH "Spinal Diseases+")

S1 (MH "Spine+") 
3 PsycINFO, PEDro, Back Group Trials Register, clinical trials registries, and PubMed search strategies PsycINFO

Last searched 17 February 2015.

1. scoliosis.mp.

2. braces.mp.

3. bracing.mp.

4. 2 or 3

5. 1 and 4

6. limit 5 to $\mathrm{yr}=2013-2015$

\section{PEDro}

Last searched 17 February 2015. For this search, the method section was left blank. In the previous searches in 2012 and 2013, the method section was limited to clinical trial.

Abstract \& Title: scoliosis

AND

Method: left blank

AND

Published since: 2013

Back Group's Trials Register

Cochrane Register of Studies (CRS)

Last searched 18 February 2015. The purpose of this search was to identify studies not in CENTRAL, therefore only studies not in CENTRAL and dated 2013 and onward were selected.

\#1 (scoliosis AND brac*) AND (INREGISTER)

Reference Manager

2012: All non-indexed text fields: (scoliosis AND brac*), published since 2008

\section{ClinicalTrials.gov}

Last searched 17 February 2015.

Search term: scoliosis

AND

Intervention: brace or bracing

AND received from 10/10/2013 to 02/17/2015 


\section{WHO ICTRP}

Last searched 17 February 2015.

Title: brace or bracing

AND

Condition: scoliosis

Date of registration is between 01/10/2013-17/02/2015

\section{PubMed}

Last searched 17 February 2015.

((((braces or bracing))) AND scoliosis) AND ("2013/10/01"[Date - Publication] : "3000"[Date - Publication]) 